\title{
LA ENFERMERÍA EN LA HISTORIA. UN ANÁLISIS DESDE LA PERSPECTIVA PROFESIONAL
}

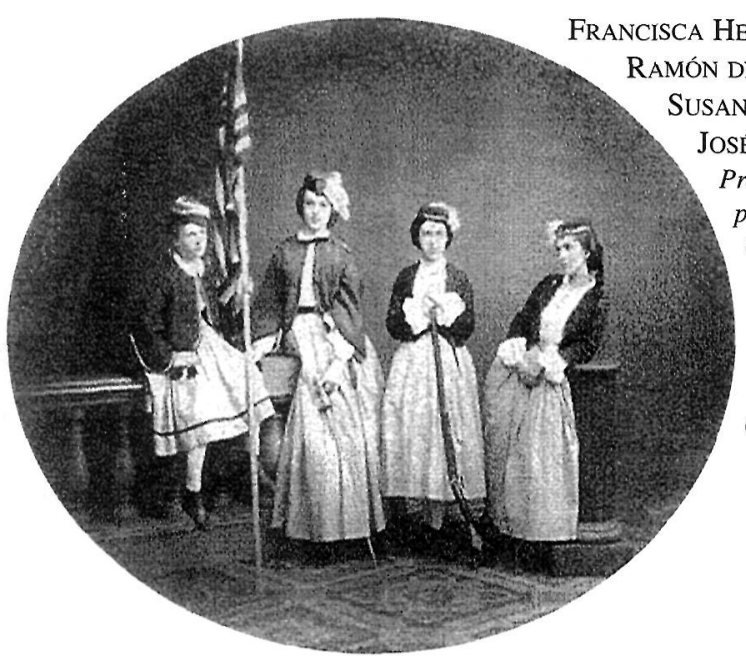

Churchill \& Denison Studio

Grupo de enfermeras en la Comisión Sanitaria, Albany, 1864 National Museum of American Art.

\section{RESUMEN}

El estudio hace en primer lugar una aproximación a lo que han sido las profesiones en la historia desde la Antigüedad Clásica hasta nuestros días, toda vez que, partiendo de unas concepciones clásicas de las profesiones liberales, la sociología ha introducido sustanciales modificaciones en los cánones establecidos sobre lo que actualmente se considera profesión. Con estas pre-

misas pretendemos analizar la enfermería, que partiendo de ser un oficio comienza a ser legalmente reconocida como profesión en los albores del Siglo XX. Y hoy, que ésta ha alcanzado un mayor grado de autonomía y conocemos mejor su historia, queremos contrastar lo que algunos autores han analizado sobre la misma; ver si podemos hablar de una consolidación profesional, teniendo en cuenta cómo va respondiendo a lo largo de su historia a las exigencias que conllevan las diferentes etapas de transformación en profesión.

Palabras clave: Historia de la enfermería.

\section{NURSING IN HISTORY. AN ANALYSIS FROM A PROFESSIONAL PERSPECTIVE}

\section{ABSTRACT}

The present study offers an approach to different professions in history starting in the Classic Ancient times and reaching our present time. It goes from the beginning of the classical concept of what a liberal profession was, until the latter sociology, which has introduced essential modifications in the established cannons about present professions. With this major premise in mind, we try to analyse nursing from the former consideration as «a simple occupation or work»-years ago- to the first part of XX century when it started to be considered as «a profession».

Today, when nursing has obtained more autonomy and we know better its history, we would like to compare the different analyses various authors have done. We would also like to see if it could be considered a «consolidated profession», bearing in mind the way nursing has behaved in its different stages of transformation. 


\section{INTRODUCCIÓN}

La investigación de la historia de la enfermería realizada en estos últimos años ha supuesto un gran avance para el conocimiento de la misma, de modo que los recientes trabajos publicados nos permiten conocer mejor la historia de la enfermería en España. Apoyados en esta realidad nos parece que es el momento de desarrollar un nuevo estudio sobre la profesión y la evolución que ha seguido, utilizando para su análisis los criterios de caracterización de las profesiones, iniciados por Max Weber y continuados por otros autores como Parsons, Wilenski, Elliot y otros.

\section{LOS OFICIOS Y LAS PROFESIONES EN LA HISTORIA}

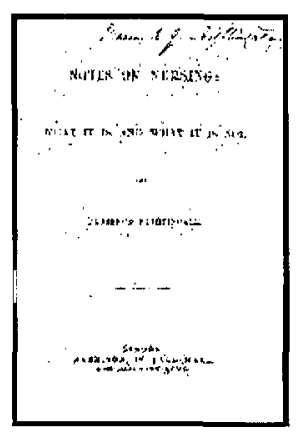

El concepto de profesión en la Historia es algo que no está tan claro, resultando incluso difícil trazar una línea divisoria entre las profesiones y los oficios. Lo que parece evidente es que el adjetivo «profesional» se utiliza para cubrir lo opuesto a aficionado y lo opuesto a trabajo no especializado. Aunque Everett Hughes sugiere que la profesión «es una etiqueta simbólica de un status deseado» (Elliot, 1975:15), lo cierto es que los sociólogos suelen definirla utilizando como referencia el requerimiento que la sociedad hace de un grupo ocupacional que cubra una necesidad concreta; es decir, lo que la sociedad determina qué debe ser un profesional, no tanto lo que el profesional quiere ser.

Max Weber (Weber, 1983) describe las ocupaciones según dos tipos: a) Las negativamente privilegiadas y b) las positivamente privilegiadas. Los oficios han tenido la característica tradicional de ser ocupaciones manuales, en tanto que las profesiones han sido, no exclusivamente, ocupaciones intelectuales, y siguen hoy en esa tendencia. La razón de que la sociedad considere a los oficios como «negativamente privilegiados» la encontramos en la Historia al observar cómo en la Grecia Clásica se hablaba de dos tipos de artes, de un lado las artes serviles ejercidas por los siervos y esclavos, y de otro las artes liberales ejercidas por los hombres libres. Las profesiones clásicas del mundo Grecorromano y más tarde consolidadas en la Edad Media son: el sacerdocio, el derecho y la medicina (Gracia Gu). De estas tres profesiones «clásicas», aunque todas con un marcado carácter intelectual, sólo la medicina ha sido capaz de asumir la ciencia moderna, convirtiéndose de este modo en paradigma de profesión. Esto hace que un autor de la talla de Parsons, y posteriormente Elliot, Amando de Miguel y otros, hayan utilizado la medicina como base para reali- zar sus estudios sobre las profesiones y establecer este patrón como medida para otras ocupaciones.

El análisis histórico se hace imprescindible ya que como indica Diego Gracia (Gracia Guillén, 1992 "La profesión es una creación humana, frente a los hechos naturales en si mismos. Y todo lo que es una creación humana, es una creación histórica, es decir, las creaciones del hombre surgen en la Historia, surgen en el tiempo y no se entienden bien cuándo, cómo y por qué han surgido si no es dentro de la Historia. Este es un fenómeno claramente humano. ¿Por qué la Enfermería es como es? Eso, o se analiza en su gestación o no se entiende. $Y$ además un profesional ha de ser una persona que tenga conciencia de su rol, y éste es un rol histórico-social creado por los hombres, por las sociedades». Por tanto, el hacer un breve recorrido histórico en busca de esas personas que proporcionaban cuidados y de los lugares donde se aplicaban los mismos, nos permitirá adentrarnos en el conocimiento de la enfermería y de los momentos en los que se efectuaron cambios que han favorecido el avance hacia el desarrollo profesional; si es que éste se ha producido. Admitiendo como cierto la afirmación de Diego Gracia de que la profesión es un hecho históricosocial, nos proponemos analizar el camino que una ocupación, cuidar, va recorriendo desde sus inicios como oficio hasta ser reconocida, legal y socialmente, y alcanzar el status de profesión. Para ello utilizaremos las conocidas cinco etapas de la profesionalización de Wilensky (Wilenski, 1964), que se ajustan más a la intención de este trabajo, sin por ello obviar aspectos que otros autores han ido incorporando al estudio de las profesiones.

\section{PRIMERA ETAPA: LA EMERGENCIA DE UN GRUPO OCUPACIONAL}

Una profesión comienza a surgir cuando ciertos individuos observan una necesidad social y se comprometen a cubrirla, actuando sobre un grupo determinado de problemas. Este grupo trabaja en dedicación exclusiva, y de hecho, cuando la sociedad precisa de sus servicios espera no encontrarle nunca «fuera de servicio» (Martin y De Miguel, 1982). Es característico, en este sentido, observar cómo gaeneralmente los profesionales alardean de no tener horarios; incluso su tiempo de ocio e intereses tienden a estar impregnados con actividades laborales o cuasilaborales (Elliot, 1975: 143).

\section{Características de profesionalización del grupo ocupacional}

La existencia de un grupo ocupacional no garantiza la profesionalidad de éste, sino que precisa cumplir de otros tres requisitos, en esta primera etapa, que le permitan ir adquiriendo el carácter auténtico de profesión. 
A) El trabajo debe ser no manual. La manualidad/ no manualidad de las profesiones tiene, pues, un carácter de necesidad, de profunda preparación por encima de un aprendizaje mecánico de copia. El carácter intelectual del ejercicio profesional es un aspecto recurrente en la literatura sobre las profesiones, así Elliot afirma que: «las profesiones que tienen tras ellas un cuerpo de conocimientos más sustancial y teórico están más capacitadas para convencer a la sociedad de la necesidad de sus servicios particularesm y quizás de persaudirla de su derecho a hacerse responsable de ello» (Elliot, 1975). Por contra, el mismo autor indica que, cuando el ejercicio profesional se basa en la realización de técnicas, por complejas que éstas sean, el persuadir a la sociedad de la necesidad de sus servicios se hace más difícil, pues la referencia a un cuerpo teórico se hace también cuando se trata de justificar decisiones referentes a los fines y «en la aplicación de las técnicas los fines ya están decididos»; lo que implica la subordinación del técnico a las órdenes del verdadero profesional. En este mismo sentido Greenwood incluye como primer criterio de profesionalización la posesión de "una base de investigación y un sistema teórico» (Greenwood, 1957). Por su parte Parsons, habla de la adquisición de un cuerpo de conocimientos y unas destrezas que permitan cimentar la «especificidad funcional» del profesional, entendiendo ésta como la característica según la cual un profesional ejerce su autoridad sobre un campo específico y especializado (Parsons, 1976). Incluso en el caso de profesiones con un carácter marcadamente manual en su quehacer, por ejemplo cirujanos, la acción, como nos indica Hughes, se determina por un conocimiento especializado y sistematizado que se formula y aplica a la resolución de problemas del cliente.

B) La conexión establecida con profesiones de mayor rango ya reconocidas hace más probable la profesionalización de una ocupación. Esta conexión debe desarrollarse en colaboración no en subordinación.

C) El status social de la clientela de la ocupación, y también de los discípulos; confirmando así la pretensión de elevado status que suele tener todo movimiento profesionalizador.

\section{DEL CUIDADO DE LA SUPERVIVENCIA A LOS ORÍGENES DE LA ENFERMERÍA}

Quizás con un poco de ingenuidad, pero apoyándonos en la documentación histórica, queremos centrar nuestro análisis en cómo la enfermería ha ido desarrollando el contenido de su hacer, el cuidado, a través de la historia como lo han hecho la medicina y otras profesiones. Por eso la historia de la enfermería, hoy, puede dar razones de esta evolución, que se ha hecho irreversible, en orden a convertirse en una profesión sin perder la originalidad de su esencia: el cuidado. De todos es sabido que la enfermería, como actividad, de acuerdo con los historiadores, ha existido desde el inicio de la humanidad, pues la especie humana siempre ha tenido personas incapaces de valerse por sí mismas y siempre se ha visto en la necesidad de cuidar de ellos, por lo cual, la enfermería, es tan antigua como la humanidad.

La historia de la enfermería está hoy en condiciones de arrojar luz sobre estos aspectos en dos momentos: 1) Etapa preprofesional que abarca desde las culturas antiguas hasta finales del siglo XIX, y 2) Etapa profesional en la que, arrancando en el siglo XIX, se inicia a principios del siglo XX con la aparición de programas formativos que propician el gran desarrollo de un cuerpo propio de conocimientos teóricos.

\section{ETAPA PREPROFESIONAL:}

Esta etapa abarca propiamente toda la historia de la enfermería como oficio que, arrancando en un periodo del que no hay testimonios escritos y carecemos de suficientes datos, llegamos a otra etapa en la que aparece una documentación que está permitiendo un más amplio estudio de la atención sanitaria y con ello de la enfermería. Por eso el estudio de esta etapa comprende necesariamente: a) una etapa oscura basada en el legado de la tradición oral, y b) una tradición escrita que arranca en la enfermería monástica y que se asienta en el estudio de las reglas monásticas, los reglamentos de hospitales y los primeros manuales de enfermería.

\section{A) La tradición oral:}

Reconociendo que la Enfermería existe desde siempre, no resulta tan sencillo demostrar estos extremos documentalmente. La fase pretécnica de la asistencia sanitaria es una amalgama de saberes y quehaceres sanadores de los que surge tanto la medicina como la enfermería, y que ésta debe de investigar como lo ha hecho aquelia. La historia de la atención sanitaria en sus orígenes se ha escrito desde la tradición clásica que gusta de ilustrar los grandes acontecimientos, los grandes personajes: la historia con mayúsculas, basada en fuentes aristocráticas, cultas, de gran altura intelectual, lo que explica el silencio y ese eludir tocar «aspectos de la vida de sus contemporáneos que repugnaba a la sensibilidad y al intelecto» (Gil, 1969). Este olvido de la pequeña historia, la del día a día, la de los pequeños acontecimientos que van configurando la cultura, esta pequeña historia, es la de los cuidados y en consecuencia la de la enfermería, que frente a los grandes personajes (Hipócrates, Galeno, Paracelso...) ha sido eclipsada.

Si bien es cierto que el hablar de cuidados en ésta etapa es complejo, no podemos ignorar, pero tampoco equiparar, el cuidado que ejerce la mujer en el ámbito doméstico (guiado del instinto, del cariño y de la tradición sanadora procedente de la magia y de la religión) y que constituye el cuidado de supervivencia, siendo la prime- 
ra aproximación al quehacer enfermero. Más próximo y sí con fines cuidadores y sanadores, está todo ese mundo que se cierne entre magia, religión, que seguirá perviviendo en la Edad Media e incluso hasta el desarrollo científico de la medicina.

Dentro del Imperio Romano, que ha logrado traer a sí las grandes figuras de la Medicina Helénica surge de forma independiente otra cultura sanitaria teniendo como origen la religión cristiana. Este hecho no sólo ha merecido la atención desde el punto de vista religioso, sino también social y médico (Laín Entralgo, 1976). Desde este aspecto es el Prof. Laín Entralgo quien al estudiar la repercusión que tuvo la doctrina cristiana en la medicina de esos siglos, nos da también las claves para el estudio de la enfermería. La plasmación de estas fundamentales novedades que introduce el Cristianismo en relación al mundo de los enfermos tuvo al menos las siguientes consecuencias:

- La consideración del sentimiento de ayuda al enfermo como un deber religioso y por tanto la creación de instituciones dedicadas a este fin.

- La condición igualitaria del tratamiento: No hay diferencia entre griegos, bárbaros, hombres libres y esclavos, pobres y ricos. Todos son atendidos sin que exista discriminación, como ocurría en el mundo pagano.

- La incorporación metódica del consuelo. En cierto sentido «técnico» una especie de psicoterapia en la acción del médico y del cuidador.

- La asistencia gratuita. Sólo por caridad al enfermo.

- La valoración moral y terapéutica de la convivencia del dolor. El dolor y sufrimiento eran sobrellevados pacientemente.

El amor al semejante centra la atención de toda una sociedad y tiene unas repercusiones importantes para la Enfermería. Los grupos de personas dedicadas al cuidado lo atestiguan: La Comunidad Cristiana, las Vírgenes, las Viudas, las Matronas Romanas... grupos determinados que dedican su vida a la atención a los enfermos y necesitados, primero en sus domicilios y después en los Hospitales (Donahue, 1989). Jacob Burckhardt estudiando esta etapa nos habla de que ya en Constantinopla y Alejandría existía un grupo numeroso, «de más de mil y quinientos» respectivamente, de servidores, el de los llamados Parabolanos o fossores, enfermeros y enterradores (Burckhardt, 1945), y Dodd que estudia los problemas sociales y económicos de esta época nos confirma estos datos (Dodd, 1975). Sobre lo que hacían o en que consistía su trabajo no hemos encontrado datos, pero sí hay constancia de la ayuda que prestaban a los enfermos tanto en sus domicilios como en las instituciones que a partir del Emperador Constantino y Juliano el Apostata se fueron creando.

\section{B) Una tradición escrita:}

Desaparecido el Imperio Romano, con la invasión de los pueblos germanos y escandinavos, la vida social se hace insegura. En este tiempo la cultura se repliega y se centra y conserva en los monasterios. Estos se convierten en centros no sólo religiosos, sino culturales y de poder, pues Ios monjes son tenidos por los Emperadores y Reyes como consultores y como médicos (Hernández Martin, 1996). Es en los primeros monasterios, donde se empieza a regular la enfermería, que inicialmente se centra en el cuidado a los propios monjes; después se abre a la sociedad. Las reglas de los monjes establecen ya por escrito los principios de la enfermería y fundamentan la ayuda al enfermo desde el «a mi me lo hacéis», del evangelio (Mat, 25,46) de tal forma que se convierte en principio y máxima para el enfermero monástico.

Es en la segunda mitad de la Edad Media cuando la enfermería alcanza un relieve y reconocimiento social más amplio. La Iglesia sale de los monasterios para cristianizar Europa a través de las Ordenes Mendincantes. Una de ellas fundada por el español, Domingo de Guzmán se diversifica y da cabida no sólo a religiosos, sino que incorpora a laicos en la denominada Orden Tercera que, siguiendo los mismos principios doctrinales, se abren a las necesidades sociales, sobre todo a la atención a los enfermos en sus propios domicilios. La aparición de estos grupos representa ya una aproximación a lo profesional, pues el trabajo que realizan es reconocido y reclamado socialmente, de tal forma que dieron respuesta a las necesidades sociales sobre todo en momentos de enfermedad y en las grandes pestes.

El legado escrito de la enfermería iniciado en las Reglas Monásticas se amplia cuando éstas intentan fundamentar todo ese quehacer con los enfermos. Así, se recopila y aparece ya en 1269 en el libro de Humberto de Romans DE OFFICCIIS ORDINIS PRAEDICATORUM, transcrito posteriormente al latín en Roma (1889). El libro, en su capítulo 27 , «acerca del oficio del enfermero» empieza por definir quién es y lo expresa así: "El enfermero es el que tiene el cuidado general de los enfermos y de la enfermería». Define al profesional y su campo de acción; dice, además de las cualidades que debe poseer, su competencia en cuanto al oficio, en cuanto al cuidado del enfermo y de la enfermería; acerca de los cuidados y conocimientos que debe tener sobre los remedios terapéuticos y de la relación y trato con los enfermos; establece una atención personalizada y una jerarquización del oficio enfermero, hablando de un enfermero que lleva la responsabilidad de la enfermería y otro al que se le asignan enfermos en concreto (Romans, 1889). Sorprende que en esta etapa se describa con tanta amplitud a esta figura como «experto»: No le limita a realizar algo rutinario, sino que está en juego la persona como ser individual. 
Sin duda que son los reglamentos de hospitales una de la mejores fuentes históricas para conocer cual ha sido el trabajo realizado como «expertos en el cuidado» y en la organización de la atención sanitaria. Estos Reglamentos son la expresión de todo el quehacer de un oficio que en el ámbito hospitalario tiene una muy amplia función. Esta documentación, aunque sigue el mismo esquema, no por ello todos aportan la misma información, pues en el devenir de los hospitales nos encontramos que existen de todo tipo según el origen y vinculación o dependencia, número de camas, tipo de enfermos que atienden y esto marca en realidad la forma de funcionar. Definen el puesto de trabajo, la función, el grado de dependencia e independencia del enfermero frente a la institución y al médico, la organización de la enfermería, las actividades y campos de actuación, la cultura, la responsabilidad y ética profesional. Todo en conjunto marca la relación con el paciente y la conducta profesional.

Los de mayor riqueza, en cuanto a contenido, proceden de las épocas en que la enfermería tiene campo de actuación más amplio, mayor dependencia de los administradores y menor del médico; también una mayor autonomía en cuanto al cuidado y responsabilidad. Los Hospitales no son centros de curación sino de cuidados y predominan éstos en la atención. Es entre los siglos XIII al XVII cuando al médico le son requeridos sus servicios y éste tiene unas horas para visitar a los enfermos en el hospital, lugar donde la figura central y con presencia continua es el enfermero. Todo lo anterior nos permite afirmar que es el cuidado, en esta época, el núcleo sobre el que gravita la asistencia al enfermo. Un estudio de las Ordenes Religiosas como los Hermanos de San Juan de Dios, los Religiosos Camilos, las Hijas de la Caridad (Comelles, 1992:35-41), los Hermanos Obregones y los Religiosos Belemitas desde su historia, sus reglas y los reglamentos de los hospitales nos confirmarían este paso hacia la profesionalización (I Congreso de Historia de la Enfermería, 1994). Estos reglamentos que versan acerca de la función de la enfermería, van definiendo sus actividades propias y especificando algunas acciones que el enfermero está autorizado a realizar en ausencia del médico; diferencian asimismo una jerarquía profesional con distintos tipos de trabajadores y diversas competencias laborales.

A partir de la segunda mitad del XVIII se medicaliza la asistencia; se inician los avances y los grandes descubrimientos de la medicina. Ahora es el médico el que toma la responsabilidad del hospital y se revisan todos los reglamentos, que se hacen más parcos, regulándose las profesiones sanitarias, con lo que la actividad de la enfermería queda supeditada plenamente a la medicina, como mero ayudante y sin cualificación alguna.

\section{ETAPA PROFESIONAL}

Como hemos visto, la enfermería en la etapa preprofesional ha tenido un papel muy limitado, en los tres aspectos que caracterizan a los grupos profesionales: en el análisis intelectual de los problemas que trataba y la toma de decisiones sobre los mismos; en la subordinación total a la medicina, aunque este extremo no siempre fue así, y en el prestigio social tanto de la clientela como de los discípulos.

A. Es a partir del siglo XIX y con especial relevancia en el siglo XX cuando se producen los cambios que nos van acercando a los cánones de profesión, iniciándose la reflexión intelectual sobre nuestro quehacer profesional, pues mientras la conservación de la vida fue la preocupación principal del hombre, los esfuerzos por conocer las leyes que regulaban la salud y la enfermedad fueron sus principales inquietudes, y este conocimiento lo ha garantizado el saber médico. Cuando este saber va cumpliendo su objetivo: garantizar la vida, en cuanto a «cantidad de vida», a lo cual la enfermería ha contribuido con una grandísima dignidad, a la sociedad le aparece otra necesidad de carácter cualitativo, la «calidad de la vida»; y esta calidad la garantiza el cuidado. En el colectivo de enfermería siempre ha estado presente la idea de que la eficacia de su acción no radicaba exclusivamente en la destreza técnica y se apeló a todo aquello que de arte ha tenido nuestra profesión para explicar qué es lo que hay en el cuidado que permite, por ejemplo, distinguir entre el prestado por un novato y el de un experto, o sencillamente entre un buen o mal cuidador y que no se explica por la escrupulosa ejecución de las prescripciones facultativas. Es aquí donde la enfermería va realizando la reflexión de cuáles son los aspectos principales de esta calidad, utilizando para ello el conocimiento de la ciencia médica, de la ciencia psicológica y de las ciencias sociales, comenzando a configurarse de esta manera el conocimiento enfermero, o si preferimos la ciencia enfermera. Pero es la definición de salud de la O.M.S. «...como máximo estado de bienestar...., y no sólo la ausencia de enfermedad.», la que marca un giro y abre un campo de posibilidades donde la enfermería comienza a explicar el por qué de sus acciones y cómo éstas actúan para proporcionar mayor calidad al cuidado. No es ya sólo el procurar conservar la vida (misión principal del quehacer médico), sino la calidad de la vida (misión principal del quehacer enfermero) lo que la sociedad comienza a reclamar.

Si la enfermería continúa tratando de desarrollarse profesionalmente, se le hará cada vez más necesario, identificar qué hacemos, cómo lo hacemos, para qué lo hacemos y por qué son necesarios nuestros servicios. Lograrlo implica describir, identificar, comparar y establecer relaciones entre los fenómenos de nuestra competencia (Luis Rodrigo, 1993). Phaneuf inspirada en Riehl y 
Roy y en Adam, considera que una profesión, cualquiera que sea su campo de actividad debe de estar en condiciones de definir: 1) el objeto de su profesión; 2) la finalidad de su actividad; 3) su rol; 4) las dificultades con que tropieza el cliente al que atiende; 5) la naturaleza de su intervención en el cliente, y 6 ) las consecuencias de esta intervención. Para dar respuesta a estas cuestiones las investigadoras han identificado cuatro conceptos que están presentes en todos sus modelos conceptuales: Persona, Entorno, Salud y Cuidados de Enfermería (Phaneuf, 1994).

Esta línea de análisis conceptual tiene sus orígenes en el siglo XIX cuando Florence Nightingale en su inquietud por sacar a la enfermería de su rutina -«...no sólo significa la administración de medicinas y cataplasmas...»-, realiza una serie de observaciones que la llevan a reconocer el valor peculiar del cuidado -«...debe significar el uso adecuado de aire fresco..., y todo ello con el menor gasto de energía vital para el paciente»-, tratando de demostrar todo con datos estadísticos, lo que la lleva a definir la enfermería como: "Poner al paciente en las mejores condiciones para que la naturaleza actúe». Por todo ello Florence Nightingale consideró que «la enfermería es una vocación que requiere sujetos aptos e inteligentes a los cuales hay que remunerar por la calidad de su servicio» (Nightingale, 1990).

Ha tenido que pasar un siglo para ver publicado en 1952 el primer Modelo Conceptual de Enfermería en la obra de Hildegarden Peplau que lleva por título «Interpersonal Relations in Nursing» (Marriner-Tomey, 1994). En este mismo año aparece la revista Nursing Research que se convierte en un órgano de difusión, de primer orden, de investigación. De gran relevancia para la profesión ha sido la aportación de Virginia Henderson con su definición, de la función propia de la enfermera, sobradamente conocida y adoptada en 1961 por el Consejo Internacional de Enfermería (Consejo Internacional de Enfermería, 1961). En estos años, la búsqueda de un método que permitiera a las enfermeras avanzar en la profesionalización de su quehacer, ha llevado a diversas autoras a iniciar el estudio de lo que se ha dado en llamar Proceso de Atención de Enfermería, pero no es hasta 1953 cuando Vera Fray, enfermera norteamericana, audazmente utilizó el término Diagnóstico de Enfermería afirmando que: «Una vez que las necesidades del paciente son identificadas pasamos al siguiente apartado, el Diagnóstico de Enfermería». La aparición de este nuevo concepto provoca continuos debates y confusiones sobre el uso del termino diagnóstico y las connotaciones médicas que implicaba. Un grupo multidisciplinario empezó a investigar en los años sesenta acerca del diagnóstico. Al comienzo de la década de los setenta Gebbie, K. y Lavin, M.A., profesoras de la Escuela de Enfermería de San Luis, crearon el Grupo Nacional para la Clasificación de
Diagnósticos de Enfermería, que en 1973 organiza la First National Conference for the Classification of Nursing Diagnosis (Primera Conferencia Nacional para la Clasificación de los Diagnósticos de Enfermería). En la Quinta Conferencia Nacional sobre Clasificación de los Diagnósticos de Enfermería (1982) se aprobó la creación de la North American Nursing Diagnosis Association (NANDA). Los Diagnósticos de Enfermería están suponiendo un avance para la profesión, que se evidencia en el reconocimiento que la Organización Mundial de la Salud ha hecho de ellos al aceptar incluirlos en su Clasificación Internacional de Enfermedades, cuando éstos adapten adecuadamente su taxonomía a la de la OMS, lo que ha llevado al Consejo Internacional de Enfermería a realizar una profunda revisión a nivel internacional de este tema.

Por todo lo anterior, no podemos concluir el análisis del componente intelectual de la enfermería sin dejar constancia del gran desarrollo epistemológico que ella está registrando. Constatamos esto, no sólo con los diagnósticos de enfermería, que cada vez más se incorporan a la práctica cotidiana y a la investigación, si no con la más de una veintena de teóricas, entre las que destacan Henderson, Peplau, Orem, Roy, Rogers..., y todo en tan sólo medio siglo.

B. De las características que debe cumplir el grupo ocupacional, el desarrollarse junto a una profesión de prestigio, nos permite un cierto optimismo al analizar nuestra evolución, ya que en estos momentos que caminamos hacia un mayor requerimiento social de nuestros servicios y con ello conseguiremos consolidar nuestra presencia en un campo fuertemente profesionalizado como es el campo sanitario, en plano de colaboración y no de subordinación. Como señalábamos arriba la subordinación total a la medicina no siempre fue tan clara como en los dos últimos siglos, donde ésta llevada de un gran desarrollo científico asume un protagonismo social y domina el campo de la salud, quedando la práctica sanitaria regulada por ella y por tanto la de profesiones más débiles como la enfermería y la farmacia, según reconoce el sociólogo Richard Hall (Hall, 1994).

C. La última característica que perfila la primera etapa, el prestigio social de la clientela y de los discípulos, marca claramente la escasa consideración social de la enfermería, toda vez que la profesión atiende, a lo largo de su historia, a las clases más desfavorecidas, a las clases marginales, a los desheredados (leprosos, presos, niños expósitos, etc.) y en cambio la medicina se ocupa de la atención a las clases más elevadas: El médico acudía a casa de los nobles y los enfermeros, y más tarde enfermeras, atendían al pobre en los hospitales o en sus domicilios. Con la socialización de la medicina y la consideración de la asistencia sanitaria como un derecho de la persona, ya en nuestro siglo, la enfermería comienza a 
atender a todos los estratos sociales y por tanto a diversificar su oferta. Esto explicaría, junto a otros factores, cómo en las últimas décadas la profesión despega vertiginosamente en su desarrollo, más que ninguna otra, y cómo se le presenta un futuro esperanzador en plano de igualdad y colaboración con otras profesiones en el marco de la sanidad.

\section{SEGUNDA ETAPA: ESTABLECIMIENTO DE PROCEDIMIENTOS INSTITUCIONALIZADOS DE SELECCIÓN Y FORMACIÓN DE LOS CANDIDADOS PARA LA PROFESIÓN}

Esta formación, según Wilensky, debe ser dada por los profesionales de la misma, aunque no necesariamente en exclusiva. Este aspecto es la consecuencia directa de la etapa anterior e implica cualificar adecuadamente a las personas que pretenden ejercer la ocupación y para ello se seleccionan a los candidatos adecuados, «ya que una actividad que pretende lograr el status profesional no puede permitirse el que sea considerada como refugio para los que no tienen cualificación (Elliot, 1975:119). Reflexiones de esta índole fue lo que, probablemente, empujó a Florence Nightingale a elegir entre la aristocracia inglesa a las estudiantes de su escuela del Hospital St. Thomas de Londres, no sólo porque si los profesionales tienen elevado prestigio social su profesión también lo tendrá, aspecto este que ha sido tildado no pocas veces como elitista y clasista, sino porque en la época victoriana solamente las mujeres de las clases altas disponían de una formación académica que garantizara una adecuada base para conocer las leyes que rigen la naturaleza, requisito éste que valoró en gran medida la autora, y que se extiende a otras escuelas de la época.

\section{EN LA GÉNESIS DE LA ENFERMERÍA MODERNA}

Analizar esta segunda etapa desde la historia de nuestra profesión, nos obliga a remitirnos al Renacimiento, el cual no supone un rompimiento con la Edad Media, al contrario, este inicio vino preparado por ella. Ronald Mousnier (García Martínez y Cols, 1996) afirma que el Renacimiento más que una doctrina y un sistema, fue un conjunto de aspiraciones y un despliegue que renovó la vida de la inteligencia y de los sentidos, el saber y el arte, y tuvo una gran repercusión en la sociedad y también en la Medicina. La salud, preocupación fundamental del hombre de todas las épocas, no quedó al margen ni tampoco la evolución de las ciencias y disciplinas que trataban de ella. La asistencia sanitaria prestada en los hospitales en los siglos XV al XVII va a experimentar un importante avance por la preocupación de los monarcas en mejorarla, tanto con la construcción de hospitales como en la reglamentación de los mismos. Esto tuvo un gran eco para el desarrollo de la enfermería, que verá en poco tiempo todo un despliegue de su acción que quedará plasmado, no ya sólo en los reglamentos de es- tos hospitales, sino también en los primeros manuales donde se recoge todo el quehacer y el saber del enfermero de la época.

El avance de la enfermería en España podemos afirmar que se gesta entre 1550-1650, donde se dio la confluencia de hechos de gran trascendencia para la profesión, que marcaron el devenir de la misma:

a) Constitución y expansión de órdenes y congregaciones españolas dedicadas exclusivamente a la prestación de cuidados: Orden Hospitalaria de San Juan de Dios, Congregación de los Enfermeros Obregones y la Orden Belemita.

b) Composición de manuales escritos por y para enfermeros.

c) Desarrollo de las funciones básicas en enfermería

Estos tres fenómenos son los suficientemente relevantes como para considerar a este período punto de transición de la Enfermería medieval a la moderna.

Es a finales de nuestro Siglo de Oro, en 1617, cuando se publica en España el primer manual sobre cuidados de enfermería escrito por un Enfermero para enfermeros. Son las primeras aproximaciones a todo un tratado de Enfermería bajo el título «INSTRUCCIÓN PARA ENFERMEROS...» (García Martínez y Hernández Martín, 1993) en el que se describen no sólo las técnicas para aplicar los remedios que los médicos ordenan, sino que es un compendio del saber de la época sobre cuidados y remedios. En él se describen:

- Técnicas y procedimientos terapéuticos realizados por enfermeros.

- Prestación de cuidados de enfermería en determinadas situaciones de urgencia.

- Preparación, indicación y administración de distintas formas medicamentosas.

- Conceptos de anatomía. Descripción de órganos y regiones anatómicas.

- Consejos y orientaciones dietéticas.

- Priorización en los tratamientos prescritos por el médico.

- Terapéutica y Enfermería.

- Tareas y funciones del enfermero

El libro de Directorio de Enfermeros de Simón López de 1650 , del que se recuperó recientemente su manuscrito y que se publica ahora, junto con un análisis del mismo, continúa en esta misma línea y que como el autor indica «...es una obra realizada con el objetivo de formar e instruir tanto a los que se inician en este oficio de enfermeros, los principiantes o aprendices, como a los que se encuentran ejerciendo ya la profesión» (García Martínez, 1997). Este manual, al igual que el anterior, supone los primeros intentos de delimitación de los co- 
nocimientos propios del enfermero y con ello la definición de la profesión, estableciendo la relación de los enfermeros con otros profesionales como médicos, boticarios, cirujanos y los marcos de actuación con respecto a los mismos. Los dos textos representan un paso importante en el desarrollo de la enfermería moderna al señalar las funciones del profesional, indicando ya aquí cuáles eran las funciones propias del enfermero y cuáles las dependientes del médico. Esta línea de formación de los aprendices se continúa a partir de esta época en todas las órdenes dedicadas al cuidado, hasta bien entrado el siglo XIX

La Ley de Instrucción Pública en 1857 regula, desde una óptica más moderna, todos los estudios, entre ellos los de Practicantes y Matronas. Una situación similar a la española es la del resto de la Europa católica; a diferencia de la Europa protestante y en especial en Inglaterra, donde tras la expulsión de las órdenes religiosas católicas, la asistencia a los enfermos quedó en manos de personal incompetente, caricaturizado por el propio Charles Dickens (Donahue, 1989: 232). En esta situación Florence Nightingale, formada en la Europa continental y en instituciones religiosas -Hijas de la Caridad y Diaconisas de Kaisserwert- (Hernández Martín, 1996), no hace otra cosa que traspasar el modelo educativo en el que ella se formó, a una Inglaterra secularizada en materia sanitaria. Este modelo rápidamente se traslada a los Estados Unidos de Norte América, y en el momento actual se ha transformado en una de las enfermerías más avanzadas. Estos hechos, junto a la pujanza de la cultura anglosajona de nuestros días, explica que en no pocas ocasiones se lea y oiga cómo Nightingale es la inventora de la enfermería moderna; afirmación esta, que a la vista de nuestro estudio no podemos asumir en toda su extensión, aunque sí hemos de admitir su enorme aportación a la modernización de nuestra profesión.

A la par de esos acontecimientos surge en España el Movimiento Reformista, que centrado en la figura de Concepción Arenal promueve la reforma de los Hospitales y en ella la reforma de la enfermería, centrada en la asistencia, el cuidado, la dimensión práctica de la profesión. Trabaja por el establecimiento de una enfermería laica con una formación que irá cristalizando con el paso del tiempo (Siles González, 1996: 227-240). Entre los años 1860-1870, estando en Inglaterra Federico Rubio y Galí, eminente cirujano, y siendo testigo del acontecimiento de la creación de la Escuela de F. Nightingale, a su regreso fundará, en 1896, en el Instituto Terapéutico en Madrid, la Primera Escuela de Enfermería en España (Hernández Martín y Pinar García, 1994:55-57). De lo qué fue la Escuela nos interesa que se funda «como centro donde formar enfermeras diplomadas que puedan prestar sus servicios a los enfermos, aprendiendo cuanto corresponda al arte de atender y cuidar de modo ar- tístico y científico». Las señas de identidad de la misma son el «bienestar para el paciente y el bien hacer de las Alumnas» (Hernández Martín y Pinar García, 1997:4243). Este será un paso importante para que después, en 1915, a instancia de la Congregación de las Siervas de María, se apruebe «oficialmente» el temario para la enseñanza de la profesión de enfermería (RO 7 Mayo 1915).

Aprobada la Ley de Bases de la Sanidad de 1944 que cristalizará en la creación del Instituto Nacional de Previsión de la Seguridad Social, los avances de la medicina y el desarrollo hospitalario, harán necesaria la aparición de un personal más técnico que responda a las necesidades sanitarias del momento. Por ello, en 1953 se gesta la unificación de estas tres carreras que existen en España: practicantes, matronas y enfermeras y se establece el plan de formación y la creación de las Escuelas de Ayudantes Técnicos Sanitarios que formarán a las enfermeras en orden a la demanda sanitaria y social (RD 4 Diciembre 1953).

Sin embargo el paso definitivo para la enfermería se lleva a cabo con la entrada, en 1977, de sus estudios en la Universidad (RD 22 Agosto 1977), que no sólo tiene importancia formativa para los discípulos, ya que la selección de candidatos se realiza entre los más cualificados del alumnado, sino que implica el acceso de la enfermería a la docencia con capacidades plenas, tanto en el ámbito de las responsabilidades docentes como en la ocupación de cargos unipersonales en las Escuelas, lo que redundará, forzosamente, en un enfoque más centrado en la enfermería y en su papel autónomo en el campo del cuidado. Por consiguiente, la juventud de la Enfermería como profesión es indiscutible.

\section{TERCERA ETAPA: LA FORMACIÓN DE UNA ASOCIACIÓN PROFESIONAL}

El desarrollo de una profesión requiere del establecimiento de modelos y normas que definan la función ocupacional y establezcan las relaciones con grupos competitivos. Este cometido es propio de las organizaciones profesionales creadas y autogobernadas por ellos mismos, las cuales establecen criterios de admisión/exclusión, impulsan un alto nivel de competencia y tratan de elevar con ello el status socioeconómico de los miembros (onzález Anleo, 1994). A lo largo de la historia esto fue un requerimiento básico y consustancial del elevado status de las profesiones clásicas; hasta el punto que las acciones de los profesionales -sacerdotes, jueces y médicos- no estaban sujetas al control de la ley civil sino de una de carácter profesional-moral y establecida y administrada por ellos mismos, perdurando esta situación hasta bien entrado el siglo XVIII. Esto va generando una cultura profesional que conlleva, entre otras cosas, un lenguaje y símbolos asociados a los diferentes tipos de 
trabajo profesional, lo cual servirá de diferenciación de los profesionales con los intrusos (Hall, 1994).

No parece posible que ningún colectivo llegue a asociarse si previamente no se dan unas condiciones determinadas y en el caso de la enfermería, dada la complejidad de su origen histórico, se ha hecho mucho más difícil.

Los Colegios Profesionales se originan en España a partir de la Ley General de Sanidad de 1855, mediante la que se instituyó en cada Provincia un juzgado médicofarmacéutico para fines disciplinarios y arbitrales, y alrededor de este organismo oficial fueron surgiendo agrupaciones profesionales.

En 1898 se implantó la colegiación obligatoria de médicos y farmacéuticos. Estos hechos permitieron la colegiación de practicantes y matronas que tuvieron que nacer supeditados a aquellos. En el marco de la Instrucción General de Sanidad de 1904 se previó la creación de colegios por parte de todas las profesiones sanitarias reconocidas, así la colegiación oficial y obligatoria de los practicantes se establece mediante la Real Orden de 28 de diciembre de 1929. Inmediatamente después por la Real Orden de 7 de mayo 1930 se concedía la colegiación obligatoria a las matronas. Sin embargo la colegiación de las enfermeras no llegaría hasta más tarde. Con la Ley de Bases de Sanidad de 1944 se instituyeron los Colegios Oficiales de Auxiliares Sanitarios: practicantes, matronas y enfermeras y su Consejo General, siendo aprobados sus estatutos en 1945. En el Real Decreto 1856/1978 de 29 de junio se aprueban los Estatutos de la Organización Colegial de ATS cuya finalidades principales son: ordenar el ejercicio de la profesión y representar a ésta y defender sus intereses.

\section{CUARTA ETAPA: EL RECONOCIMIENTO PÚBLICO Y EL APOYO LEGAL}

No es suficiente con una autorregulación del quehacer profesional a través de asociaciones. En nuestros días, para un control del acceso a la profesión y de las formas en que ésta debe ejercerse se hace imprescindible e incluso exigible, una legitimación no sólo social sino legal. Las profesiones pretenden tener responsabilidad única sobre algún aspecto del bien público, y saber cómo conseguir ese bien (Elliot, 1975:152). El desarrollo de una profesión se ha de basar en ese reconocimiento público ya que ésta no es lo que sus miembros digan de ella sino lo que necesite y determine la sociedad. Este reconocimiento público se consolida en una autorización de la comunidad, formal o informal -licencia, certificación, registro-, que garantiza que el profesional ha sido sometido a un programa formativo específico para ese ejercicio y ha superado las pruebas que avalan su cualificación. De esta forma se está luchando contra el intrusismo.

El reconocimiento social ha de cristalizar en una legislación que permita, de un lado, delimitar sus compe- tencias y responsabilidades (el Código Penal, por ejemplo, recoge los actos de denegación de auxilio), defendiéndola del intrusismo y exigiendo su actuación cuando sea preciso, y de otro, regulando su ejercicio profesional específico mediante una legislación laboral concreta.

La utilidad y el prestigio social reconocidos son excelentes indicadores del reconocimiento público de esa profesión (Martín y De Miguel, 1982: 94). Si el prestigio que una profesión tiene en la sociedad es superior a la utilidad social percibida de esa profesión (indicados estos aspectos sobre una escala numérica, por ejemplo), estamos en el fondo ante una crítica latente de la sociedad sobre el excesivo poder que tiene esa ocupación. Si ocurre al revés, es decir, el prestigio social es inferior a la utilidad social percibida, nos encontramos ante la justificación de las ideas de reivindicación porque el prestigio es bajo. Este es el caso de la Enfermería, ya que en la sociedad actual se percibe la importancia y utilidad sanitaria que esta profesión tiene para la buena consecución de la salud de la población, pero por contra, su prestigio social es bajo, o al menos inferior a su utilidad, cuantitativamente hablando; situación ésta que favorece nuestras reivindicaciones ya que tendrían una buena acogida social.

\section{LA INSTITUCIONALIZACIÓN DE LA PROFESIÓN}

El paso efectivo hacia la institucionalización de la enfermería conlleva no sólo el reconocimiento legal, con la aprobación de los planes de estudio, sino con el despliegue de la misma a nivel práctico. A inicios del siglo $\mathrm{XX}$ existe un reconocimiento a la par social y oficial de la enfermería que se pone de manifiesto a raíz de la creación del Instituto de Reformas Sociales, que para la puesta en marcha de su plan de acción requiere de la colaboración de la enfermería tanto en la Escuela Nacional de Puericultura, Escuela Nacional de Sanidad, Patronato de Asistencia Social Psiquiátrica, como en la participación de la lucha antituberculosa y antivenérea. Todo un despliegue de la enfermería en esos ámbitos (Siles González, 1996).

Sólo recientemente la enfermería dispuso de una regulación legal que tiene sus raíces en 1857 cuando se reconoce la titulación de los practicantes en la Ley de Instrucción Pública de 9 de septiembre, desarrollándose en 1888 sus funciones profesionales mediante el reglamento para las carreras de practicantes y matronas de 16 de noviembre. La Instrucción General de Sanidad Pública de 1904, define las profesiones sanitarias y reorganiza nuevamente los estudios, establece la legitimidad de los títulos existentes y contempla la posibilidad de crear otras titulaciones. Amparada en esta Ley, en 1915 (RO 7 de Mayo de 1915) es reconocida como carrera. La unificación de las tres carreras de Auxiliares Sanitarios (practicantes, matronas y enfermeras) se produce en 1953 con la unificación, anteriormente citada, de los planes de estudio, de tal manera que las primeras disposiciones le- 
gales que regulan las funciones de esta nueva profesión surgen en 1956 (Decreto 26 Julio 1956), completándose en 1960 (Decreto 17 Diciembre 1960) con la regulación del ejercicio profesional del ayudante técnico sanitario, practicante, matrona y enfermera. Esta legislación mantiene en la actualidad, sin apenas modificación, las funciones del profesional de enfermería que le sitúan en un papel de subordinación: «auxiliar del médico», y práctica técnica.

Es a partir de 1957 cuando se regulan las especialidades de enfermería que se mantendrán hasta 1987 (RD 3 de Julio de 1987), año en el que se establecen las especialidades de los Diplomados en Enfermería: Enfermería Pediátrica, de Salud Mental, de Salud Comunitaria, de Cuidados Especiales, Geriátrica, Gerencia y Administración de Enfermería y Obstétrico-Ginecológica (Matrona), de las cuales solamente esta última es desarrollada en 1992.

Son dos hitos en el avance de la enfermería en España la regulación legal de las Direcciones de Enfermería, que permiten a la profesión autorregular su ejercicio, y las Consultas de Enfermería, que favorecen una relación con el paciente más directa y autónoma, lo que con el tiempo y el desarrollo de nuestras competencias independientes, propiciará el reconocimiento por parte de la sociedad de nuestra contribución específica a la salud desde el cuidado.

\section{QUINTA ETAPA: LA ELABORACIÓN DE UN CÓDIGO FORMAL DE ÉTICA DE DEBERES PROFESIONALES}

En los famosos estudios que realizó Parsons sobre las expectativas que la sociedad tenía respecto a los médicos, se obtuvo una imagen ideal que incluía ciertas características tales como: universalismo, neutralidad afectiva y orientación a la colectividad (Parsons, 1976). El universalismo es la característica que consiste en tratar a todo el mundo sin acepción de personas (que no diferencia entre personas por sus rasgos personales), y que se espera de las profesiones y no así de los oficios. La neutralidad afectiva implica que un profesional no se dejará llevar por lo bien o mal que a uno le caiga una persona y tampoco utilizará las transferencias positivas o negativas bien para aprovecharse o rechazar a las personas que tiene que tratar. Orientación hacia la colectividad supone el ejercicio de su rol a pesar de que ello no representase provecho personal alguno. Parsons, para explicar esto, pone un ejemplo interesante: la diferencia entre los objetivos de un comerciante -el mero económico- y los objetivos de un profesional -la dedicación a la sociedad-. Estas notas características tienen mucho que ver con la ética. Del profesional se espera que tenga una ética elevada, una excelencia ética -en el sentido de contraposición a derecho que es la característica propia de los ofi- cios-. Esta ética se considera en el profesional a priori y constituye una imagen sociológica de la profesión realmente bella (Gracia Guillén, 1992).

La elaboración del Código de ética es una de las características más importantes de una profesión y constituye en sí mismo un mecanismo de autocontrol profesional. Indica la aceptación por parte de la profesión de la responsabilidad y la confianza que en ella ha depositado; la sociedad. La enfermería española asumió en su día el Código Internacional del CIE; en los momentos en los que ha logrado entrar en la Universidad y controlar la enseñanza de la misma elaboró su propio Código (Organización Colegial de Enfermería, 1989), el cual recoge, además, los derechos de los enfermos y aspectos bioéticos relativos a la responsabilidad del sistema sanitario y la ecología. Eso mismo le obligará a ser revisado con frecuencia. El código actual aunque no deja de ser descriptivo y muy genérico, se basa en mayor grado en la confianza que la enfermera merece al público y en ese sentido constituye un cambio, frente al anterior y confiere a la enfermería un mayor reconocimiento, autoridad y credibilidad. Esto ha significado un gran avance para la profesión en España. Será necesaria la creación de la Comisión Deontológica que controle la realidad de la conducta profesional.

\section{DISCUSIÓN}

Que la enfermería es una profesión es algo que estamos en condiciones de afirmar hoy; un hoy joven; un hoy de pocos lustros. Nos aventuramos a realizar esta afirmación tras el análisis desde el punto de vista sociológico realizado a partir de los datos disponibles por la historia de la enfermería.

1) La existencia del grupo ocupacional de enfermería desde los inicios de la historia parece una cuestión inapelable y de gran importancia, tan conocida y asumida que no debe ser puesta en entredicho. Otra cuestión es si este grupo ocupacional merece el calificativo de profesional, algo no tan claro para los sociólogos, y de ser así cuándo lo alcanza.

A) La condición de profesión se logra cuando una actividad, indispensable para la sociedad, se realiza con un elevado nivel intelectual en sus decisiones. En qué medida la enfermería ha respondido o responde a esta exigencia? En los albores de la historia se quiere ver a la madre y esposa como prototipo de la primera enfermera, si bien esto no constituye un verdadero grupo ocupacional, ya que no hace otra cosa que cubrir una necesidad doméstica de subsistencia. Sin embargo, es en la Antigüedad Clásica cuando aparecen ya grupos dedicados al cuidado. Sabemos que no gozaron de prestigio social, puesto que eran actividades serviles, propias de esclavos, aunque ejercieron una actividad laboral concreta de la que se beneficiaron las clases sociales más desfavorecidas. 
Desde que aparecen estos colectivos laborales y hasta muy recientemente, el cuidado es una actividad que no cumple con la primera condición que nos impone $\mathrm{Wi}$ lensky, y esta no es otra que la posesión de un cuerpo de conocimientos sustancial y teórico que avale la toma de decisiones, con un carácter eminentemente intelectual.

En los últimos siglos la adquisición de conocimiento mediante el apoyo de la ciencia ha gozado de un elevado prestigio y los conocimientos así adquiridos, de altísima fiabilidad. La ciencia, no obstante, no tiene el monopolio de la verdad, pero generalmente toda actividad moderna y sobre todo las de carácter sanitario, la utilizan para obtener conocimiento profundo sobre los problemas que tratan. A este respecto hay que hacer dos consideraciones: ni es ciencia toda forma de conocimiento, ni es un científico todo aquel que maneja elementos cuyo funcionamiento está basado en principios científicos.

No podemos afirmar que la enfermería fuera una profesión, ni su saber propio una ciencia, mientras observemos cómo a lo largo de la historia ésta se ha limitado a ejecutar las órdenes médicas y el cuidado no ha sido más que una tarea que resolvía el sentido común. La historia de la enfermería no dispone de datos para aventurarse a afirmar que la enfermería poseía un cuerpo de conocimientos propio que justificaba sus decisiones. Las fuentes documentales proporcionan datos que nos permiten argumentar que el saber referente a la salud estaba en las mentes de los filósofos, de los médicos, etc. No podemos afirmar lo mismo de la enfermería. Probablemente nuestra historia, todavía esta escrita sobre una historia hecha por médicos y para médicos, pero esto no nos autoriza a escribirla a nuestro capricho, sin base documental y sólo basada en una idea más reivindicativa que científica.

La emergencia del pensamiento teórico enfermero se produce principalmente en la segunda mitad de este siglo. En este crecimiento, que supone el complejo marco de modelos filosóficos y teóricos, va encontrando más su carácter y la respuesta al pleno reconocimiento profesional. Si bien esto es realidad, la juventud de la enfermería quizá ha provocado la excesiva cantidad de modelos teóricos, como consideraba la propia Virginia Henderson (Henderson, 1994), quien al respecto comentó que «se ha escrito tanto que es incomprensible -no sabes de lo que hablan-o no es lo suficientemente interesante para que te permita recordarlo» (Smith, 1996), y plantea como desafío la contrastación empírica -requisito imprescindible en toda teoría (González González, 1989)-, «todo aquel que haya escrito sobre la teoría de enfermería practique lo suficiente para decirnos cómo hay que convertir sus teorías de la enfermería en enfermería práctica» (Smith, 1996: 88).

B) Un factor de profesionalización que gran cantidad de autores valoran como un aspecto independiente y que en Wilensky podríamos incluir en la primera etapa, es la autonomía de la profesión. Una profesión, como actividad que reclama la sociedad y que cubre una parte de sus necesidades, debe mantener una relación directa con el colectivo al que atiende y ser responsable, al menos, de una parcela concreta de ese problema. En caso de compartir parcelas del problema con otros profesionales, la actividad de la que tratamos debe de relacionarse con la otra u otras en plano de colaboración y nunca de subordinación.

La enfermería a duras penas hoy podemos considerarla una profesión autónoma. A lo largo de la historia no existe una línea continua ascendente que vaya de unos niveles de menor a mayor autonomía, como se demuestra desde el monasticismo y desde la aparición de los hospitales. En el monasticismo mantuvo conexiones con médicos o con monjes expertos, y en la asistencia hospitalaria su dependencia fue o de los administradores o de los médicos. Admitiendo como cierto que órdenes hospitalarias masculinas tuvieron mayor margen de independencia, esto generó sus problemas, pero siempre estuvieron supeditados a las órdenes médicas. Posteriormente, en el siglo XIX, el hombre-enfermero, como afirma Martín Barroso, tecnifica fuertemente aquellos campos donde se asienta, confiriéndoles una mayor autonomía y un mayor grado de profesionalización: practicantes, fisioterapeutas, podólogos (Martín Barroso, 1978).

Mientras que la mujer no ha sido reconocida socialmente capaz de ocuparse de alguna actividad intelectual productiva, ha estado sometida al dictamen de un médico que le indicaba cual era el recto proceder profesional. En los momentos de la historia en los que la asistencia sanitaria proporcionada por instituciones con mayoría de hombres va siendo sustituida por congregaciones de mujeres, va perdiendo el grado de autonomía del que gozó. Esta situación se afianza con el gran desarrolio de la medicina de Ios siglos XIX y XX que somete toda acción sanitaria al dictamen médico, llegando hasta nuestros días manuales en los que las ideologías dominantes imponen al profesional de enfermería «...el médico es superior del ATS por dignidad y por ciencia.... (Domínguez Alcón, 1986). Sin embargo, hoy, estamos ante una modificación de estos parámetros de referencia, debido a la fuerte incorporación de la mujer, no sólo al mercado de trabajo, sino al mundo cultural y científico y le ha permitido una mayor y mejor preparación y la posibilidad de acceder a puestos de responsabilidad en plano de igualdad.

2) La enfermería, al igual que otras actividades profesionales, fue antes un hacer que un saber, lo que durante muchos siglos dio la impronta particular al cuidado de los enfermos. Pero aunque recientemente, como hemos justificado en el punto anterior, se comenzó con más vigor a analizar nuestro quehacer peculiar, desarrollando 
así un cuerpo teórico propio, ya hace siglos que se consideraba la gran trascendencia de este hacer y lo imprescindible de un saber que lo acompañara. $\mathrm{Al}$ menos dos siglos antes de que Florence Nightingale comenzase a enseñar a ser enfermera a la alta sociedad inglesa, en España, Andrés Fernández y Simón López, ambos enfermeros, escribieron sendos manuales, para instruir a sus discípulos.

Analizando este hecho -que no deja de ser insólito en esta época- se percibe cómo este saber hacer, al que responde el total del contenido del libro, conlleva además todo un intento de exigencia docente: aparece cómo explicar cuando alguien no lo entiende; define algunos conceptos, separando en distintos apartados la diferencia entre el concepto y el desarrollo de la técnica; hasta incluso entrando en las causas. En estos manuales queda asimismo constancia de cómo se preocupan estos hermanos de la organización docente de sus centros, de manera que garanticen la óptima formación de los discípulos.

Se podría pensar que estos manuales aparecen para cubrir necesidades específicas de unas órdenes muy concretas, y quizás en cierta medida así sea. No obstante hay que considerar que la obra «Instrucción para Enfermeros» tuvo durante un siglo cuatro ediciones. Pero lo importante de este hecho es constatar que ya en el siglo XVII existe la preocupación por formar a aquellos que van a ejercer el cuidado de los enfermos. Esta preocupación, aunque a base de acontecimientos muy difuminados en el tiempo, la vamos constatando con la proliferación en este y el siguiente siglo de instituciones dedicadas a la formación de profesionales, algunas de las cuales gozaban de gran prestigio en toda Europa, como fue la Escuela de París de las Hijas de la Caridad o la Escuela de las Diaconisas de Kaiserwerth; lo cual viene a demostrar que aquellos manuales no fueron un hecho aislado, sino el inicio de una conciencia profesional que viene a cimentar el desarrollo que se continua hasta nuestros días, de este segundo e imprescindible requisito de profesionalización.

Ahora, en estos momentos, nos encontramos en la fase de consolidación, no sin altibajos, de la docencia de la profesión. La formación en enfemería ha avanzado en los últimos tiempos de forma tan imparable, que incluso en algunos países ya ha alcanzado el nivel académico que se destina a las áreas más desarrolladas del conocimiento humano. Nuestro país desde la entrada de los estudios en la universidad está siguiendo la tendencia de las enfermerías más avanzadas y está sirviendo de modelo para otros países de nuestro entorno, perfilándose de esta manera una línea de no retorno.

Este camino no se recorre sin la lógica impaciencia de quienes vivimos acontecimientos de este alcance histórico, ya que nos parece que nunca se llegará a alcanzar nuestro ideal: quedan pendientes el acceso a un segundo y ter- cer ciclo y un programa completo de especialidades que cristalice en una carrera profesional que está por llegar.

$\mathrm{El}$ interés que la enfermería está mostrando por formarse, para ejercer una mejor práctica profesional, lo demuestra el gran auge de los cursos de postgrado que están surgiendo en todo nuestro territorio nacional, y que han podido extenderse por la desaparición de especialidades oficiales, diseñadas desde la administración central y que con criterios de formación de especialistas vía «residencia», pudieran propiciar una adecuación a las necesidades asistenciales de la población y una adaptación a los modos de hacer del sistema sanitario español. Los cursos organizados por diferentes entidades públicas y privadas no siempre han respondido a las expectativas, de la profesión y del sistema sanitario, de ser diseñados desde el rigor científico que busca un alto grado de cualificación intelectual y laboral. El hecho de no haber imperado la coherencia y la honestidad, no ha llevado a perder tiempo, pero nunca a pararnos. Si analizamos los avances en los últimos cincuenta años con perspectiva histórica, no podemos sino estar esperanzados con nuestro futuro.

3) El reconocimiento social y legal es otro aspecto que configura grandemente a una profesión y que en nuestro caso también tiene sus luces y sus sombras. La regulación legal de la enfermería debe abordar el análisis de tres aspectos: a) la titulación que confiere la capacidad profesional a nivel nacional, b) el desarrollo de las funciones y c)la carrera profesional.

A) Aún siendo cierto que tenemos plenamente reconocido nuestro ejercicio mediante un título oficial que nos capacita para la práctica, que ya viene siendo una realidad desde principios de siglo.

B) Las funciones, desde el punto estrictamente legal, están desarrolladas de forma muy limitada en un R.D. de 1973, con alguna modificación posterior, donde por un lado se desarrollan profusamente las administrativas, de conservación del material y del medio, y por otro los comentarios lacónicos sobre la función asistencial nos remite constantemente a un papel auxiliar y completamente subordinado al médico, lo que en el momento actual no se corresponde con la preparación del profesional. Esta contradicción es un impedimento a la hora del reconocimiento social. A pesar de esta realidad, y aunque la práctica va siempre delante de la voluntad del legislador, está siendo evidente cómo los jueces, en aquellos casos en los que se ve implicado un profesional de enfermería, están aplicando el criterio de reconocer las capacidades profesionales en virtud de la preparación académica, de forma que, ya no es excusable la inacción o mala acción basada en una prescripción o ausencia de ésta; la autonomía profesional que no nos otorga la ley, tal vez la sociedad, a través de sus tribunales de justicia, nos la exige. 
En el plano laboral y a nivel institucional, el desarrollo de nuestras cuatro funciones han tenido un desarrollo desigual:

I) Función asistencial: En el ámbito de la atención especializada sería asumible todo lo expuesto más arriba referido al Real Decreto de funciones. Si bien es constatable cómo en los últimos años la enfermería va adquiriendo una mayor capacidad y solvencia en aquello que de autónomo tiene su quehacer, no es menos cierto que la presión asistencial obliga al profesional a someterse a los imperativos terapéuticos, limitándose a realizar tareas delegadas por la prescripción facultativa y otras con un marcado carácter burocrático. En estos años en que los éxitos científicos han garantizado un buen nivel de salud de la población, la sociedad se plantea como reto otras prioridades sanitarias: los ancianos, el incremento de enfermos crónicos debido a la eficacia de la terapéutica ante los problemas agudos, y a ellos está respondiendo la enfermería con gran dignidad, aportando no sólo la eficacia en el cuidado, sino la calidad en el mismo desde los aspectos humanos y la relación, consiguiendo que el cuidado centre el interés clínico de grupos que asociados se dedican al estudio de aspectos concretos -derechos de los enfermos, ética, humanización de la asistencia, cuidados paliativos y que de no ser tratados en plano de interdisciplinaridad pueden acabar despojando a la enfermería de su principal capital. Donde más se está consolidando nuestro papel autónomo es en Ia atención primaria de salud, donde la enfermería puede lograr de manera más sencilla y directa el objetivo de su labor, el cuidado, y dar a conocer a la población cuál es el servicio directo que podemos ofrecer. Esta oferta, tarde o temprano, por la tendencia mundial de utilizar una clasificación de diagnósticos de enfermería reconocidos por la O.M.S., forzará a los países modernos, que se precien de tener un buen sistema sanitario, a asumirlos.

II) Función Administrativa: Una tendencia de toda ocupación con aspiraciones de profesionalidad y por tanto de autonomía, es autorregularse. A partir de la Constitución Española y fundamentalmente con la Ley de Sanidad de 1986, se desarrolla un sistema sanitario en el que tienen cabida las distintas profesiones que intervienen en la salud y configura el nuevo hospital en el que la enfermería aparece en su organigrama como parte del equipo directivo. Este hecho aunque parezca parcial tiene una gran repercusión para su desarrollo, pues se le reconoce de esta manera su peculiaridad y mayor autonomía al desvincular su control de las jefaturas de servicio y al posibilitar su participación en la gestión hospitalaria en un nivel más equilibrado con otras profesiones. Esto le permite entrar, con pleno derecho, en la gestión de un bien público que es la salud de los ciudadanos, desde las instituciones nacionales e internacionales.
III) Función Docente: No sólo implica la educación del paciente en aras de un mejor autocuidado, sino que tiene su expresión fundamental en la formación de los candidatos a ejercer la profesión. Hasta los años setenta la enfermería participaba en la formación de pregrado como monitor de prácticas y no en la formación teórica, destinada ésta, casi exclusivamente, a los médicos, al menos en la dirección de las escuelas de enfermería. A raíz de la incorporación en la universidad, los profesionales de enfermería pudieron acceder a la docencia y ocupar plazas de profesor Titular de Escuela Universitaria, cargo que confiere todas las capacidades docentes de las que disfrutan otros titulados y permitiendo la ocupación de cargos unipersonales -Dirección de Escuela y de Departamento, etc.-. A pesar de este logro, no todo está hecho, ya que al no disponer del grado de doctor, queda francamente limitada la carrera docente del profesional, aunque como en otras ocasiones hemos comentado, no está dicha la última palabra; tampoco en este asunto.

IV) Función Investigadora: Relacionada íntimamente con la función anterior, es la función esencial para el desarrollo del cuerpo de conocimientos propio. Parece evidente que si la investigación no va a tener proyección en un logro concreto, la falta de motivación para iniciar o continuar investigaciones propiciará el abandono de ésta función capital. Si pensamos en una enfermería dedicada secularmente al cuidado continuo del paciente, con poco tiempo para ocuparse de otras cuestiones, comprenderemos la falta de incentivos para dedicar sus horas de libres a la investigación, si de ello no se deriva la obtención del grado de doctor o la valoración curricular que permita un progreso en su carrera profesional. Obtener la plena capacidad investigadora permitiría diseñar proyectos desde la enfermería y centrados en el cuidado, y dirigir proyectos de investigación a nivel oficial -universidad, centros de investigación, obtención de financiación para proyectos de investigación, etc.-, no como ocurre en la actualidad donde los proyectos oficiales han de dirigirlos doctores de otras ramas. Este problema surgió también en la enfermería americana de los años cincuenta-sesenta, y de ello se lamentaba V. Henderson que observó como la investigación enfermera estaba excesivamente polarizada hacia aspectos sociológicos del cuidado, donde la preocupación principal era la figura de quien cuida más que el cuidado y su resultado en el paciente (Henderson, 1994: 48-59); lo que se debía a que los profesores de metodología de la investigación eran sociólogos en su mayoría y formaban y proponían a sus alumnos, trabajos basados en aspectos sociales más que en los clínicos. Ella propone centrarse en una investigación clínica de la que la medicina y otras disciplinas obtienen sus principales éxitos y fuente de conocimientos. En la actualidad, a pesar de todo lo anterior, la enfermería ha mostrado un pundonor y un interés por fundamentar y agrandar el conocimiento enfermero, dignos de en- 
comio. La proliferación en las dos últimas décadas de revistas de enfermería -la Revista ROL lleva en el mercado 20 años, y otras se han iniciado posteriormente como Enfermería Científica, Enfermería Clínica, etc.- y demás publicaciones son testigos de ésta afirmación, y en ellas, cada vez con más frecuencia, podemos encontrar trabajos de investigación, con un buen diseño metodológico, que en muchas ocasiones alcanzan un gran nivel.

C) La ausencia absoluta de una regulación de la carrera profesional es un grave riesgo que está en el origen de la desmotivación que padecen muchos profesionales, lo que les lleva de un lado a caer en una rutina, que busca también el no tomar más responsabilidades que las estrictamente necesarias, y por otro el tan estudiado problema del abandono profesional. Esta ausencia se hace evidente en un colectivo, que en el ejercicio de la asistencia clínica el día de la obtención del título y la consecución de su primer contrato laboral, ha concluido su carrera y sólo puede desarrollarla vía administrativa (supervisión, adjunto a la dirección, subdirección y dirección), cargos éstos muy vinculados a los avatares político-administrativos más que a un adecuado curriculum. El auténtico reconocimiento y aprovechamiento de los conocimientos adquiridos en el ejercicio profesional, vendría dado por una estructura sanitaria que permitiera distintos niveles de responsabilidad y también retributivos, que fueran incentibando la adquisición de conocimientos y competencias profesionales. Todos estos niveles competenciales se alcanzarían obteniendo una cualificación en años de ejercicio y formación, configurando un curriculum que propiciara el acceso a dichos niveles.

\section{CONCLUSIONES}

Tras este análisis en el que hemos pretendido dejar patente los avances de la enfermería, finalizamos extractando las conclusiones que a nuestro juicio sintetizan el tránsito de la enfermería de oficio a profesión:

1.- La enfermería emerge como grupo ocupacional en los inicios de la Historia pero con un carácter claramente de oficio. Su tarea es exclusivamente manual y los candidatos a ejercerla son de escaso nivel social al igual que su clientela.

1.1.- En nuestros días el grupo ocupacional va adquiriendo las peculiaridades de una profesión: su quehacer cada vez se asienta más en un saber propio y con base científica. Y los candidatos son seleccionados entre los más cualificados del alumnado.

1.2.- El grupo ocupacional goza en estos momentos de una cierta autonomía, siendo éste aspecto el que más se ha de desarrollar en el futuro y que irá de la mano del mayor conocimiento e implantación de los diagnósticos enfermeros.
2.- A partir del siglo XVII contamos con manuales para la enseñanza de la profesión. En estos momentos ha habido una verdadera eclosión de textos desde y para la enfermería, que ratifican cómo nuestra profesión se ha incorporado plenamente al panorama académico. El reto actual es alcanzar el máximo nivel con el doctorado y equiparar así nuestra área de conocimiento al resto de las áreas de conocimiento de la Universidad.

3.- La cuarta etapa de Wilensky es la que precisa de un mayor desarrollo. Es la que ha sufrido más altibajos en los últimos doscientos años, y en el momento actual adolece de una legislación que limita a la enfermería a una labor auxiliar, sin reconocer todas las capacidades que paradójicamente la sociedad ya otorga. Falta esa legislación que colme las esperanzas de la enfermería en una regulación de las funciones y de las especialidades. Este camino ya se ha iniciado con la incorporación de la enfermería a la gestión sanitaria de alto nivel.

4.- La posesión de una Asociación Profesional y de un Código Deontológico son aspectos que completan el carácter de una profesión y que la enfermería tiene suficientemente cubierto desde hace varias décadas; aún precisando en algunos aspectos, de un mayor dinamismo.

En estas conclusiones hemos querido aportar a la historia de la enfermería como son más los aspectos que hoy la hacen profesión, que los que le faltan por cubrir. De esta manera podemos acabar este trabajo haciendo nuestra la frase del Prof. Diego Gracia de que «ninguna ocupación tiene un futuro de profesionalización tan esperanzador como la enfermería».

\section{BIBLIOGRAFÍA}

Burckhardt, J. (1945) Del paganismo al cristianismo. La época de Constantino el Grande. Fondo de Cultura Económica, México.

Comelles, J.M. (1992) Cuidar y curar. Bases para una historia antropológica de la enfermería hospitalaria. Revista de Enfermería Rol 172, 35-41.

Consejo Internacional de Enfermería (1961) Principios Básicos de los cuidados de Enfermería. (Publicación científica, $n^{\circ}$ 57). Organización Panamericana de la Salud, O.M.S., Washington.

Dodd, E. R. (1975) Paganos y cristianos en una época de angustia. Cristiandad, Madrid.

Domínguez-Alarcón, C. (1986) Los cuidados y la profesión enfermera en España. Pirámide, Madrid.

Donahue, P. (1989) Historia de la Enfermería. Doyma, Barcelona.

Elliot, P. (1975) Sociología de las profesiones. Tecnos, Madrid

García Martínez y Cols. (1996) Génesis de la Enfermería Moderna en España. En Historia de la Enfermería 
en España (desde la antigüedad hasta nuestros días) (Hernández Martín ed.), Síntesis, Madrid.

García Martínez, A. C. (1997) Análisis del Directorio de Enfermeros de Simón López. Síntesis, Madrid.

García Martínez, A.C. y Hernández Martín, F. (1993) Aproximación a la Enfermería Española de los Siglos XVI-XVII. Facsímil del libro de Instrucción para enfermeros de Andrés Fernández (1625), C.G.E., Madrid.

Gil, L. (1969) Terapheia. La medicina popular en el mundo clásico. Guadarrama, Madrid.

González-Anleo, J. (1994) Las profesiones en la sociedad corporativa. En Ética de las profesiones (Fernández J.L. y Hortal A. (ed.) Universidad Pontificia de Comillas, Madrid.

González González, A. (1989) Diseño y cálculo de tests estadísticos para ensayos clínicos y de laboratorio. E.U. de Enfermería. U. Complutense, Madrid.

Gracia Guillén, D. (1992) Desarrollo, aportación e imbricación de la enfermería en el avance tecnológico. I Jornada Nacional de Investigación en Historia de la Enfermería: «La enfermería en el siglo XX. De oficio a profesión, los momentos del cambio. Seminario Permanente en investigación en Historia de la Enfermería, E.U.E. F. y P. y Departamento de Enfermería de la U.C. de Madrid.

Greenwood, E. (1957) The Attributes of a Professions. Social Work, 2,. Citado por Hall, R.H. (1994): «Sociology of Work». Pine Forge Press, California.

Hall, R. H. (1994) Sociology of Work. Pine Forge Press, California.

Henderson, V.A. (1994) La Naturaleza de la Enfermería. Reflexiones 25 años después. Interamericana-McGraw-Hill, Madrid.

Hernández Martín, F. (1996) Historia de la Enfermería en España. Desde la Antigüedad hasta nuestros días. Síntesis, Madrid.

Hernández Martín, F. y Pinar García, M. E. (1994) Orígenes Modernos de la Enfermería en España. La Primera Escuela de Enfermería en España. Jano XLVII 1098, 55-57.

- (1997) Primera Escuela de Enfermería. «Santa Isabel de Hungría» Revista de Enfermería Rol 224, 42-43.

- (1996) Historia de la Enfermería en España Desde la antigüedad a nuestros días. Síntesis, Madrid Laín Entralgo, P. (1976) Historia Universal de la Medicina, Tomo I. Salvat, Barcelona.

Luis Rodrigo, M.T. (1993) Diagnóstico de Enfermería: un instrumento para la práctica asistencial. Doyma, Barcelona.

Marriner-Tomey, A. (1994) Modelos y teorías de enfermería, $3^{a}$ ed. Mosby-Doyma, Madrid.
Martín, J., De Miguel, A. (1982) Sociología de las profesiones. C.I.S., Madrid.

Martín Barroso, C. (1978) Enfermería: presente y futuro. Colegio Oficial de A.T.S., Madrid.

Nightingale, F. (1990) Notas sobre enfermería: qué es y que no es. Salvat, Barcelona.

Organización Colegial de Enfermería (1989) Código deontológico de la enfermería española, Madrid.

Parsons, T. (1976) El sistema social, $2^{a}$ ed. Revista de occidente, Madrid.

Parsons, T. (1976) Estructura social y proceso dinámico: $\mathrm{El}$ caso de la práctica médica moderna. En $\mathrm{El}$ sistema social, $2^{a}$ ed. Revista de occidente, Madrid.

Phaneuf, M. (1994) Cuidados de Enfermería. El proceso de atención de enfermería. Interamericana-McGrawHill, Madrid

Romans, H. (1889) Libri de officciis de Orden praedicaturum. Roma

Siles González, J. (1996) El Movimiento Reformista durante el Siglo XIX. Su influencia en la Enfermería Española. En Historia de la Enfermería en España (Hernández Martín, F. ed.). Síntesis, Madrid pp. 227240.

Siles González, J. (1996) El proceso de Institucionalización de la enfermería española (1900-1936). En Historia de la Enfermería en España (Hernández Martín, F. ed.). Síntesis, Madrid.

Smith, J.P. (1996) Virginia Henderson. Los primeros noventa años. Masson, Barcelona.

Weber, M. (1983) Economía y Sociedad, $2^{\text {a }}$ ed., $6^{\mathrm{a}}$ reimp. Fondo de Cultura Económica, México.

Wilensky, H.L. (1964) The Professionalization of everyone? The American Journal of Sociology, 70. Citado por Elliot, P. (1975): «Sociología de la Profesiones». Tecnos, Madrid.

\section{FUENTES NORMATIVAS}

Decreto de 26 de julio (BOE de 13-VIII-1956)

Decreto de 22 de agosto de 1977 (B.O.E. de 23 de agosto de 1977).

Decreto del Ministerio de la Gobernación 2319/1960 de 17 de noviembre (BOE de 17-XII-1960).

Ley General de Sanidad de 1855.

Real Orden de 7 de mayo, publicada el 21 de mayo de 1915.

Real Decreto de 4 de diciembre de 1953 (B.O.E. de 29XII-1953).

Real Decreto 992/1987 de 3 de julio. 